\title{
Longitudinal patterns of physical activity in children aged 8 to 12 years: the LOOK study
}

\author{
Rohan M Telford ${ }^{1 *}$, Richard D Telford ${ }^{2,3}$, Ross B Cunningham ${ }^{4}$, Thomas Cochrane ${ }^{1}$, Rachel Davey ${ }^{1}$ \\ and Gordon Waddington ${ }^{5}$
}

\begin{abstract}
Background: Data on longitudinal monitoring of daily physical activity (PA) patterns in youth over successive years is scarce but may provide valuable information for intervention strategies aiming to promote PA.

Methods: Participants were 853 children (starting age $\sim 8$ years) recruited from 29 Australian elementary schools. Pedometers were worn for a 7-day period each year over 5 consecutive years to assess PA volume (steps per day) and accelerometers were worn concurrently in the final 2 years to assess PA volume (accelerometer counts (AC) per day), moderate and vigorous PA (MVPA), light PA (LPA) and sedentary time (SED). A general linear mixed model was used to examine daily and yearly patterns.

Results: A consistent daily pattern of pedometer step counts, AC, MVPA and LPA emerged during each year, characterised by increases on school days from Monday to Friday followed by a decrease on the weekend. Friday was the most active and Sunday the least active day. The percentage of girls and boys meeting international recommendations of 11,000 and 13,000 steps/day respectively on a Monday, Friday and Sunday were 36\%, 50\%, $21 \%$ for boys and 35\%, 45\%, 18\% for girls. The equivalent percentages meeting the recommended MVPA of $>60 \mathrm{~min} /$ day on these days were 29\%,39\%, 16\% for boys and 15\%,21\%, 10\% for girls. Over the 5 years, boys were more active than girls (mean steps/day of 10,506 vs 8,$750 ; p<0.001$ ) and spent more time in MVPA (mean of 42.8 vs $31.1 \mathrm{~min} /$ day; $\mathrm{p}<0.001$ ). Although there was little evidence of any upward or downward trend in steps/day from age 8 to 12 years, there was a trend toward lower MVPA, LPA and a corresponding increase in SED from age 11 to 12 years.

Conclusion: A weekly pattern of PA occurred in children as young as age 8 on a day by day basis; these patterns persisting through to age 12. In addition to supporting previous evidence of insufficient PA in children, our data, in identifying the level and incidence of insufficiency on each day of the week, may assist in the development of more specific strategies to increase PA in community based children.
\end{abstract}

Keywords: Longitudinal, Physical activity, Children, Patterns, Habitual, Recommendations, Trends, Daily, Pedometers, Accelerometers

\section{Background}

A reported decline in physical activity (PA) among youth [1], coupled with a growing body of evidence supporting the health benefits of PA [2,3], has resulted in an increasing need to understand PA behaviour and patterns among children.

\footnotetext{
* Correspondence: rohan@look.org.au

${ }^{1}$ Centre for Research and Action in Public Health, University of Canberra, Bruce ACT 2617, Australia

Full list of author information is available at the end of the article
}

PA among children is often referred to in the literature in terms of 'patterns' and is thought to be 'habitual' in nature, however the extent to which PA behaviour adheres to patterns or whether these patterns are repetitive to such an extent that they are habitual is not well understood.

Previous cross sectional studies among youth have examined PA patterns in terms of day type (weekday vs weekend) [4-9], school-time versus non school-time $[10,11]$ and time spent in relative exercise intensities $[6,12,13]$. There is also emerging longitudinal evidence

\section{Biomed Central}


that time spent engaged in moderate to vigorous activity (MVPA) in childhood tracks into adolescence particularly for girls [14] and that daily MVPA and MVPA performed during school breaks (recess and lunch) declines with age [15]. However, there have been no studies incorporating all days of the week using longitudinal data to determine whether specific day of the week habitual patterns or routines of PA might exist or persist in children in the pre-teenage (elementary or primary school) years.

We extend on our previous work with pedometers in 8-10 year-olds [16] by tracking the cohort over 5 years through to age 12 and analysing patterns of PA intensity with the addition of accelerometry. Identification of patterns of activity, in particular those days consistently associated with low or high PA may be important in understanding how interventions are best implemented to reshape the culture of school and weekend days with respect to increasing physical activity in children.

The objective of the current study was to investigate pedometer-assessed PA over 5 consecutive years, with years 4 and 5 supplemented with concurrently assessed accelerometer data, in a large cohort of elementary school children in order to answer the following questions: (a) do children exhibit a general day to day pattern of PA each week? (b) do daily patterns of PA persist each year? i.e. do they change with age? and (c) what percentage of our Australian cohort of midrange socioeconomic status meet currently recommended daily PA levels, and how is this affected by day of the week?

\section{Methods}

\section{Participants}

This study is part of the multidisciplinary Lifestyle of our Kids (LOOK) project [17], which commenced in 2005 with the aim of investigating how early physical activity and physical education contributes to health and development. The overall LOOK study utilizes a longitudinal design and incorporates measures of PA, fitness, motor control, psychological health, family influences, bone health, cardiovascular function, academic achievement and nutrition. The present investigation examines only the patterns of physical activity.

Participants were initially 853 children ( 435 boys and 418 girls), recruited from 29 government-funded elementary schools in the city of Canberra, Australia. To be included in the study parents provided written consent indicating their child's acceptance to participate and that their child was able to take part in vigorous physical activity in order to perform fitness tests that were part of the overall study design. Of the children invited to participate, $88 \%$ accepted, and represented approximately $30 \%$ of the total number of grade 2 children enrolled in Canberra government elementary schools in 2005. Using Australian
Taxation Office statistics in 2005, average taxable family income in the suburbs of residence of our cohort approximated the national average. From demographic information obtained from a parent completed questionnaire, approximately $90 \%$ of the study participants had one or both parents of Caucasian descent, 7\% of Asian descent, 1\% indigenous Australian or Polynesian, with $2 \%$ unknown. Height and weight was recorded using a stadiometer and digital scales. Means (and standard deviation) of participant characteristics at the time of the first measures of PA were: age $8.0(0.3)$ years for both sexes; height $1.31(0.06) \mathrm{m}$ and $1.30(0.06) \mathrm{m}$; weight 29.7 (5.7) and 29.5 (6.5) $\mathrm{kg}$ for boys and girls respectively.

Of the 853 children who gave consent to participate in baseline measurements at age 8 years, 640 (75\%) participated in the final year of measurement at age 12 years. Study attrition over the four years of measurement was due to children moving to a school outside the study jurisdiction, including interstate $(\mathrm{n}=193)$, or withdrawing from the study $(\mathrm{n}=20)$.

This study was approved by the Australian Capital Territory Health and Community Care Human Research Ethics Committee and the Ethics Committee of the Australian Institute of Sport. Participation by the children was entirely voluntary and informed consent was received from all the parents or guardians.

\section{Pedometry}

We used pedometers of identical step detection mechanism throughout the study, distributed by Walk 4 Life (Plainfield, IL USA) in the first year, and by New Lifestyle, A-82 (Lee's Summit, MO USA) in ensuing years. The change was due to the latter model having an identical step count mechanism with additional 7 day memory which obviated the need for daily recordings. The two models of pedometer have previously been shown to provide equivalent step counts [16] and the validity and reliability of the pedometer mechanism has been verified with children of about the same age as our cohort [18]. Prior to pedometers being issued to children each year, a routine calibration check was carried out on every pedometer by a technician who performed a 40 step trial with the pedometer located on the right hip and only pedometers that were accurate to within $0.5 \%$ were used.

Pedometers were issued to the children for one week on five separate occasions one year apart. The testing periods were confined to the same period in each year, in the Australian Spring to early Summer months of September to December in 2005, 2006, 2007, 2008 and 2009 and included a weekend. The weekdays were normal school days. Children wore pedometers on their right hip for seven consecutive days, and the first day's measurement was randomly distributed from Monday 
through to Friday. The first day's measurement was not included in our analysis given that part of it was incomplete, but also because the novelty of wearing the pedometers may have influenced initial activity. Pedometer step counts were routinely recorded by teachers and parents in the first year and by a technician in the remaining years. As previously suggested [8], daily step counts less than 1000 and greater than 30,000, were considered erroneous and discarded. In order to maximise data, all valid days were used in the analyses, our statistical model adjusting for incomplete data sets.

\section{Accelerometry}

In the final two years of elementary school (grades 5 and 6), children's activity was also assessed using accelerometers (Actigraph GT1M, Pensacola, FL, USA). Accelerometers were positioned on a belt around the waist in line with the right knee. Daily accelerometer counts (AC) were used as a measure of volume of PA and cut off points for sedentary classified activity (SED) were defined as 0-100 counts per minute, light physical activity (LPA) defined as $101-2,296$ counts per minute and moderate to vigorous physical activity (MVPA) classified as greater than 2,297 counts per minute based on published recommendations $[19,20]$. An epoch length of 60 seconds was used and the first day's data were discarded to minimize any potential reactivity. Days of accelerometer data were included if there were 10 or more hours of activity; and in the absence of any established non-wear time criteria for children in the literature [21], the decision was made to consider an entire hour to be invalid if there were more than 30 zero counts in a row (30 minutes of non-wear time). For comparisons of PA between school time and outside of school time, school hours was considered to be between 9 am and $3 \mathrm{pm}$ and outside of school hours was the sum of before school ( 7 am- 9 am) and after school ( $3 \mathrm{pm}-10 \mathrm{pm})$. For this analysis, days of accelerometer data were included if there were more than 10 hours of activity and data were recorded for each time period. Actigraph accelerometers have been validated for use in both children and adolescents [22]. Accelerometer data were analyzed without the low frequency extension (LFE) function using Meterplus software, Version 4.2 (San Diego State University, USA).

\section{Statistical analysis}

Our data are multi-level and the response variables representing physical activity vary at a between-subject and at two temporal levels; the temporal levels consist of five separate years for pedometer data (two separate years for accelerometer data) and, within years (seven observations corresponding to each day of the week). We specify subject, year-within subject and day-withinyear-within subject as random effects in our formulated statistical model to account for possible dependencies in observations due to the above multi-level structure. As our main focus was on patterns of systematic variation between genders, between grades, between day of the week and possible interaction between these factors, these terms were specified in our model as fixed effects. Post hoc analysis introducing wear time into our model was performed to examine any potential influence of wear time on these patterns. For analysis of aggregate school-time/non-school time data, the same modelling framework was adopted. In this case, however, our model does not include random and fixed terms which include day of week. Our statistical model then fits within the general framework of general linear mixed models [23]. Restricted maximum likelihood is used to estimate variance components and weighted least squares for estimating fixed effects. Statistical significance of effects are assessed by calculating adjusted Wald statistics [24].

Preliminary analysis showed pedometer and accelerometer data was positively skewed so a square root transformation was used for both accelerometer and pedometer data to satisfy linearity as well as distributional assumptions of our model. General model checking procedures were routinely used to identify aberrant data and to check the model assumptions. Adjustment for incomplete data and missing values were accommodated for in the estimation process and so all valid days of data for all children were utilised. Statistical computations were undertaken using the statistical package Genstat, Version 14 (VSN International Ltd, Oxford, UK).

\section{Results}

Pedometer step counts

The percentages of children who were issued devices and returned valid pedometer data in each measurement year are shown in Table 1.

As a square root transform was applied to each PA variable in our analyses to meet assumptions of normality, values in text are back-transformed and presented as geometric means. Figures contain transformed data and descriptive data are presented as medians with $5^{\text {th }}$ and $95^{\text {th }}$ percentiles in tables.

\section{Year to year and gender variation in step counts}

Pedometer data for each measurement year are shown in Table 1. There were significant year to year variations in daily step counts $(\mathrm{p}<0.001)$, but there was no evidence of any consistent trend towards an increase or decline in PA (Figure 1). The number of steps/day declined for both boys and girls between 2005 and 2006, increased from 2006 to 2008, followed by another decline from 2008 to 2009. No significant year by gender interactions were found. Combining data from all years, boys were generally 
Table 1 Descriptive statistics for pedometer measured physical activity for each measurement year separated by gender

\begin{tabular}{|c|c|c|c|c|c|c|c|c|c|c|}
\hline & \multicolumn{2}{|c|}{2005} & \multicolumn{2}{|c|}{2006} & \multicolumn{2}{|c|}{2007} & \multicolumn{2}{|c|}{2008} & \multicolumn{2}{|c|}{2009} \\
\hline & \multicolumn{2}{|c|}{ Grade 2} & \multicolumn{2}{|c|}{ Grade 3} & \multicolumn{2}{|c|}{ Grade 4} & \multicolumn{2}{|c|}{ Grade 5} & \multicolumn{2}{|c|}{ Grade 6} \\
\hline & \multicolumn{2}{|c|}{ Age 8 years } & \multicolumn{2}{|c|}{ Age 9 years } & \multicolumn{2}{|c|}{ Age 10 years } & \multicolumn{2}{|c|}{ Age 11 years } & \multicolumn{2}{|c|}{ Age 12 years } \\
\hline & Boys & Girls & Boys & Girls & Boys & Girls & Boys & Girls & Boys & Girls \\
\hline $\mathrm{N}$ pedometers issued & 435 & 418 & 397 & 383 & 347 & 336 & 330 & 314 & 328 & 312 \\
\hline $\begin{array}{l}\mathrm{N}(\%) \text { returned pedometers meeting } \\
\text { validation criteria }\end{array}$ & $372(86 \%)$ & $366(88 \%)$ & $290(73 \%)$ & $308(80 \%)$ & $285(82 \%)$ & $283(84 \%)$ & $272(82 \%)$ & $256(82 \%)$ & $266(81 \%)$ & $274(\% 88)$ \\
\hline $\begin{array}{l}\text { Steps per day (median and } 5^{\text {th }} \text { and } 95^{\text {th }} \\
\text { percentiles) }\end{array}$ & $\begin{array}{c}12014 \\
(4264,21303)\end{array}$ & $\begin{array}{c}9762 \\
(3259,18195)\end{array}$ & $\begin{array}{c}10552 \\
(2059,20933)\end{array}$ & $\begin{array}{c}8523 \\
(2126,16541)\end{array}$ & $\begin{array}{c}11206 \\
(2890,21171)\end{array}$ & $\begin{array}{c}9078 \\
(2495,16868)\end{array}$ & $\begin{array}{c}11459 \\
(3143,20705)\end{array}$ & $\begin{array}{c}10002 \\
(3017,17647)\end{array}$ & $\begin{array}{c}10477 \\
(2329,19244)\end{array}$ & $\begin{array}{c}9008 \\
(2628,15947)\end{array}$ \\
\hline $\begin{array}{l}\% \text { meeting step per day } \\
\text { recommendations }{ }^{\text {a }}\end{array}$ & 42 & 37 & 34 & 30 & 38 & 33 & 39 & 38 & 30 & 30 \\
\hline
\end{tabular}

${ }^{\mathrm{a}}$ Step recommendations based on accumulating $>11,000$ steps/day for girls and $>13,000$ steps/day for boys. 


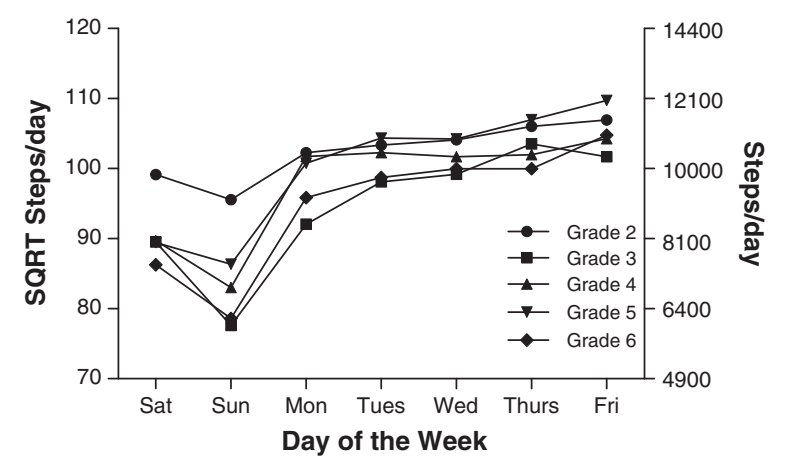

Figure 1 Mean pedometer steps per day, girls and boys combined for each measurement year from grade 2 (age 8 years) to grade 6 (age 12 years). The left $Y$ axis represents the square root of steps per day used for statistical analysis and the non linear right $Y$ axis represents actual steps per day.

more physically active than girls, boys averaging 10,506 steps/day vs. girls 8,750 steps/day $(\mathrm{p}<0.001)$.

\section{Day of the week and gender variation in step counts}

Median values for steps taken on each day of the week are shown in Table 2. Our model indicated that the number of steps/day varied according to day of the week (boys and girls both $\mathrm{p}<0.001$ ). To avoid statistical issues associated with multiple post-hoc pair-wise testing we refer to the figures and tables to provide an indication of the day to day differences. Figure 2 shows the day to day variation in mean step counts for boys and girls for the five measurement years combined. For both boys and girls, there was a trend of an increase in daily step counts from Monday through to Friday, the difference between Monday and Friday being 12\% (1,524 steps/day) for boys and 13\% (1,312 steps/day) for girls. This was followed by a decrease from Friday through to Sunday, with the difference between Friday and Sunday being $36 \%$ (4,714 steps/day) for boys and 34\% (3,393 steps/ day) for girls. Sunday was the least active day of the week. There were clear gender differences, boys took significantly more steps/day than girls on all days of the week $(\mathrm{p}<0.001)$ and this difference was greater on school days than on weekend days. For example, on Wednesday, the difference in mean steps/day between boys and girls was $20 \%$ (2,360 steps/day) compared with a difference of 15\% (806 steps/day) on Sunday.

\section{Longitudinal persistence of a day of the week step pattern}

Our longitudinal analysis indicated that day of the week step patterns persisted from age 8 to 12 years. As shown in Figure 1, while the volume of steps fluctuated between years $(p<0.001)$ there is evidence of a persistent year to year pattern characterised by an accumulation of steps/day during the school week followed by a progressive decline on weekends.

\section{Accelerometers}

Eighty five per cent of children in grade 5 and $84 \%$ in grade 6 returned accelerometers with valid data and were included in analyses. Differences were found in wear time according to day of the week $(\mathrm{p}<0.001)$. For boys and girls combined, wear time was highest on Fridays (13.92 h $\mathrm{SD}=1.75)$ and lowest on Sundays (12.48 h $\mathrm{SD}=1.74)$. No significant differences in wear time were found between boys and girls $(p>0.3)$. The compliance of children returning valid data according to day of the week is shown in Table 2. Compliance was found to be lowest on weekend days.

Descriptive data for accelerometer variables for each measurement year are shown in Table 3. Overall boys accumulated $12 \%$ more AC per day than girls (boys 413,000 , girls 364,000 counts/day, $\mathrm{p}<0.001$ ), and spent $25 \%$ more time in MVPA (boys 42.8 , girls $32.1 \mathrm{~min} /$ day, $\mathrm{p}<0.001)$. No significant difference was found between boys and girls for time spent in LPA per day (boys 342, girls $348 \mathrm{~min} /$ day, $\mathrm{p}=0.22$ ) and girls spent $3 \%$ more minutes per day in SED classified activities than boys (boys 384, girls $396 \mathrm{~min} /$ day; $\mathrm{p}=0.013$ ). Patterns were similar to those for the pedometer data; gender differences for $\mathrm{AC}$ and time spent in MVPA were greater on school days than weekends. For example, on Wednesday boys participated in 33\% more MVPA (17.1 min/day) compared to Sunday where the difference was $15 \%$ ( $3.9 \mathrm{~min} /$ day).

\section{Year to year and gender differences in Accelerometer measures}

For both boys and girls there was a decline in $\mathrm{AC}$, MVPA and LPA (all $\mathrm{p}<0.001$ ) from age 11 to 12 years as shown in Table 3. These decreases corresponded to a decline in MVPA of $4 \%$ (1.7 min/day) for boys and 10\% (3.0 $\mathrm{min} /$ day) for girls, and a decline in LPA of $6 \%$ (22 $\mathrm{min} /$ day) for boys and 7\% (24 min/day) for girls. There was a corresponding increase in time spent in SED from age 11 to 12 (boys and girls both $\mathrm{p}<0.001$ ) in the order of $6 \%$ (24 min/day) for boys and 10\% (40 min/ day) for girls.

\section{Day of the week variations in accelerometer measures}

Median values for accelerometer variables for each day of the week are shown in Table 2. Similar to findings from pedometer data, and as shown in Figures 3, 4 and 5, variation occurred in each of AC, MVPA and LPA according to day of the week (all $\mathrm{p}<0.001$ ), a similar pattern emerging for each PA measure. This was characterised by an increase in PA during school days. For example, time spent in MVPA was $7.7 \mathrm{~min} /$ day and $7.3 \mathrm{~min} /$ day higher on Friday compared to Monday for boys and girls respectively. Following a rise in MVPA over schooldays was a decrease over the weekend; boys spent $26.0 \mathrm{~min}$ per day and girls 16.9 min per day less time in MVPA on Sunday 
Table 2 Unadjusted median values with $5^{\text {th }}$ and $95^{\text {th }}$ percentiles for physical activity measured by pedometers and accelerometers categorised by gender and day of the week for all measurement years combined

\begin{tabular}{|c|c|c|c|c|c|c|c|c|c|c|c|c|c|c|}
\hline & \multicolumn{2}{|c|}{ Mon } & \multicolumn{2}{|c|}{ Tues } & \multicolumn{2}{|c|}{ Wed } & \multicolumn{2}{|c|}{ Thurs } & \multicolumn{2}{|c|}{ Fri } & \multicolumn{2}{|c|}{ Sat } & \multicolumn{2}{|c|}{ Sun } \\
\hline & Boys & Girls & Boys & Girls & Boys & Girls & Boys & Girls & Boys & Girls & Boys & Girls & Boys & Girls \\
\hline \multirow[t]{2}{*}{ Pedometer steps/day } & 11550 & 9409 & 12276 & 9442 & 12104 & 9995 & 12204 & 10476 & 12971 & 10392 & 9134 & 8338 & 8008 & 6941 \\
\hline & $\begin{array}{l}(3774- \\
19545)\end{array}$ & $\begin{array}{l}(3031- \\
16906)\end{array}$ & $\begin{array}{l}(4114- \\
21412)\end{array}$ & $\begin{array}{l}(3141- \\
16384)\end{array}$ & $\begin{array}{l}(3627- \\
20841)\end{array}$ & $\begin{array}{l}(2808- \\
17325)\end{array}$ & $\begin{array}{l}(4106- \\
21379)\end{array}$ & $\begin{array}{l}(3750- \\
17296)\end{array}$ & $\begin{array}{l}(3505- \\
22049)\end{array}$ & $\begin{array}{l}(3451- \\
18751)\end{array}$ & $\begin{array}{l}(2189- \\
20033)\end{array}$ & $\begin{array}{l}(2099- \\
16984)\end{array}$ & $\begin{array}{l}(1852- \\
18418)\end{array}$ & $\begin{array}{l}(1919- \\
15620) \\
\end{array}$ \\
\hline $\begin{array}{l}\% \text { meeting step per day } \\
\text { recommendations }\end{array}$ & 36 & 32 & 43 & 34 & 44 & 38 & 44 & 44 & 50 & 45 & 26 & 28 & 21 & 18 \\
\hline \multirow{2}{*}{$\begin{array}{l}\text { Accelerometer wear time (hr/day, } \\
\text { mean and standard deviation) }\end{array}$} & 13.16 & 13.16 & 13.19 & 13.18 & 13.05 & 13.29 & 13.06 & 13.26 & 13.88 & 13.98 & 13.08 & 13.22 & 12.57 & 12.35 \\
\hline & $(1.74)$ & $(1.58)$ & $(4.6)$ & $(4.5)$ & $(4.52)$ & (1.44) & $(1.61)$ & $(1.5)$ & $(1.75)$ & $(1.71)$ & $(1.86)$ & $(1.84)$ & $(1.74)$ & $(1.71)$ \\
\hline $\begin{array}{l}\text { \% returned accelerometers meeting } \\
\text { validation criteria }{ }^{c}\end{array}$ & 70 & 70 & 71 & 70 & 70 & 75 & 72 & 70 & 73 & 74 & 60 & 62 & 53 & 54 \\
\hline \multirow{2}{*}{$\begin{array}{l}\text { Accelerometer Counts (counts per } \\
\text { day/1000) }\end{array}$} & 397 & 338 & 419 & 361 & 434 & 363 & 447 & 387 & 457 & 407 & 338 & 316 & 307 & 302 \\
\hline & $(210-807)$ & $(189-663)$ & $(216-885)$ & $(184-656)$ & $(250-869)$ & $(204-754)$ & $(238-849)$ & $(206-707)$ & $(254-830)$ & $(233-727)$ & $(144-796)$ & $(148-795)$ & $(123-796)$ & $(122-763)$ \\
\hline \multirow[t]{2}{*}{ MVPA (min/day) } & 42 & 30 & 44 & 32 & 49 & 33 & 52 & 35 & 51 & 37 & 27 & 22 & 23 & 18 \\
\hline & $(11-104)$ & $(7-85)$ & $(11-121)$ & $(6-76)$ & $(13-117)$ & $(7-85)$ & $(11-117)$ & $(7-87)$ & $(15-118)$ & $(10-95)$ & $(3-90)$ & $(2-81)$ & $(2-90)$ & $(2-78)$ \\
\hline \multirow[t]{2}{*}{ Light (min/day) } & 339 & 340 & 340.5 & 340 & 351 & 341 & 338 & 354 & 369.5 & 376 & 338 & 342 & 315 & 316 \\
\hline & $(231-466)$ & $(231-440)$ & $(133-468)$ & $(184-472)$ & $(228-459)$ & $(224-440)$ & $(221-469)$ & $(234-466)$ & $(247-488)$ & $(256-492)$ & $(192-447)$ & $(210-494)$ & $(180-447)$ & $(188-457)$ \\
\hline \multirow[t]{2}{*}{ Sedentary (min/day) } & 385 & 408 & 369 & 390 & 372 & 400 & 367 & 389 & 380 & 391 & 385 & 381 & 380 & 371 \\
\hline & $(250-534)$ & $(275-536)$ & $(178-517)$ & $(209-527)$ & $(231-501)$ & $(271-552)$ & $(240-505)$ & $(244-536)$ & $(243-528)$ & $(253-537)$ & $(226-566)$ & $(233-549)$ & $(233-566)$ & $(226-530)$ \\
\hline$\%$ meeting MVPA recommendations ${ }^{b}$ & 29 & 15 & 33 & 16 & 38 & 18 & 41 & 19 & 39 & 21 & 22 & 12 & 16 & 10 \\
\hline
\end{tabular}

${ }^{a}$ Step recommendations based on accumulating $>11,000$ steps/day for girls and $>13,000$ steps/day for boys.

${ }^{b}$ MVPA recommendations based on accumulating $>60$ minutes of MVPA per day.

c Validation criteria based on $>10$ hours of wear time per day. 


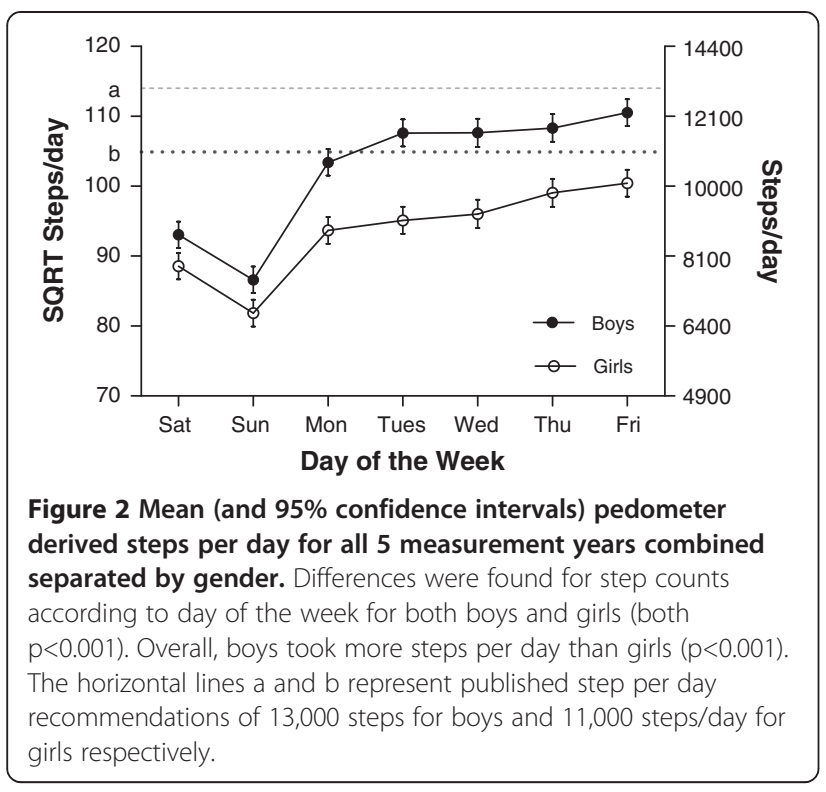

compared to Friday. In contrast with the general pattern evident for AC, MVPA, and LPA, the daily pattern for SED (Figure 6) showed no consistent pattern, fluctuating throughout the week. Post hoc analysis introducing wear time into our model showed no change in any of the patterns observed.

\section{PA intensity in and out of school time}

Descriptive data for PA intensity in school hours (9 am$3 \mathrm{pm})$ and outside of school hours (7 am-9 am and
3 pm-10 pm) is shown in Table 4. Both boys and girls spent more time in SED and LPA classified intensity outside of school time compared to during school time. Outside of school time boys spent 38 minutes more in SED classified activity and 42 minutes more in LPA compared to school time (both $\mathrm{p}<0.001$ ). Girls spent 25 minutes more in SED classified activity and 24 minutes more in LPA outside of school time compared to school time (both $\mathrm{p}<0.001$ ). For MVPA, in the boys there was no significant difference in MVPA accumulated within and outside school time (23.6 vs $23.2 \mathrm{~min}$; $\mathrm{p}=0.47$ ). Girls however spent more time engaged in MVPA outside of school time than in school time (18.4 $\mathrm{v}$ 14.7 min; $\mathrm{p}<0.001$ ).

\section{Comparison with international PA recommendations}

Overall, $37 \%$ of boys and $34 \%$ of girls met published PA recommendations [25] of 11,000 steps per day for girls and 13,000 steps per day for boys. This varied with day of the week, $36 \%$ of boys and 35\% of girls meeting recommendations on a Monday, $50 \%$ boys and $45 \%$ girls on Friday and $18 \%$ and $21 \%$ on a Sunday.

Overall, $31 \%$ of boys and $16 \%$ of girls met published MVPA recommendations [26] of 60 min per day. Again, the percentages varied with day of the week. Twenty nine percent of boys and $15 \%$ of girls performed at least 60 min MVPA on a Monday compared to 39\% of boys and $21 \%$ of girls and on Friday and only $17 \%$ of boys and $10 \%$ of girls met recommendations on a Sunday.

Table 3 Unadjusted Median values with $5^{\text {th }}$ and $95^{\text {th }}$ percentiles for accelerometer measured physical activity for each measurement year separated by gender

\begin{tabular}{|c|c|c|c|c|}
\hline & \multicolumn{2}{|c|}{2008} & \multicolumn{2}{|c|}{2009} \\
\hline & \multicolumn{2}{|c|}{ Grade 5} & \multicolumn{2}{|c|}{ Grade 6} \\
\hline & \multicolumn{2}{|c|}{ Age $11.1 \pm 0.4 \mathrm{y}$} & \multicolumn{2}{|c|}{ Age $12.1 \pm 0.4$ y } \\
\hline & Boys & Girls & Boys & Girls \\
\hline $\mathrm{N}$ accelerometers issued & 330 & 314 & 328 & 312 \\
\hline \multirow[t]{2}{*}{$\mathrm{N}(\%)$ returned accelerometers meeting validation criteria } & 282 & 266 & 270 & 265 \\
\hline & $(85 \%)$ & $(85 \%)$ & $(82 \%)$ & $(85 \%)$ \\
\hline \multirow[t]{2}{*}{ Accelerometer wear time (hrs per day) } & 13 & 13 & 13 & 13 \\
\hline & $(10,17)$ & $(10,17)$ & $(10,17)$ & $(10,17)$ \\
\hline \multirow[t]{2}{*}{ Accelerometer Counts (counts per day/1000) } & 418 & 375 & 390 & 342 \\
\hline & $(196,663)$ & $(183,789)$ & $(159,782)$ & $(157,642)$ \\
\hline MVPA (min/day) & $43(6,116)$ & $31(5,88)$ & $43(6,110)$ & $30(4,81)$ \\
\hline \multirow[t]{2}{*}{ Light (min/day) } & 355 & 359 & 333 & 333 \\
\hline & $(223,474)$ & $(232,488)$ & $(199,465)$ & $(213,449)$ \\
\hline \multirow[t]{2}{*}{ Sedentary (min/day) } & 364 & 376 & 388 & 406 \\
\hline & $(220,508)$ & $(228,523)$ & $(252,545)$ & $(259,548)$ \\
\hline$\%$ meeting MVPA recommendations ${ }^{a}$ & 33 & 18 & 30 & 14 \\
\hline
\end{tabular}

MVPA moderate and vigorous physical activity.

${ }^{a}$ MVPA recommendations based on accumulating $>60$ minutes of MVPA per day. 


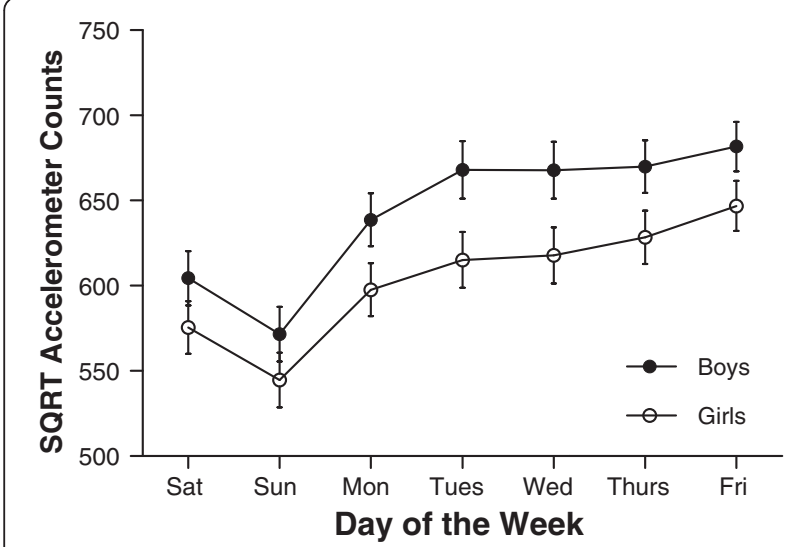

Figure 3 Mean accelerometer counts per day (and 95\% confidence intervals) for each day of the week separated by gender. Differences were found for accelerometer counts according to day of the week for both boys and girls (both $p<0.001$ ). Overall, boys accumulated more accelerometer counts per day than girls $(p<0.001)$.

\section{Discussion}

The most salient aspects of this novel longitudinal study of pre-teenage children were (a) the finding of a distinct weekly pattern of habitual PA and (b) this pattern was not simply a one off occurrence but persisted for five consecutive years in 8 to 12 year old children. This pattern was characterized by a gradual build-up of daily PA through the school week followed by a progressive drop over the weekend, and extends on previously reported data comparing weekdays and weekends [4-9]. As well as highlighting the general world-wide concern that children are insufficiently physically active, our data indicate that the incidence of children failing to meet recommended daily PA standards varies markedly according to day of the week.

\section{Day of the week patterns of PA}

A large reduction in weekend activity in our cohort, consistent with previous reports [5,9] along with the variation during the weekdays raises the question as to why these day to day variations occur. Our study was not designed to determine causes of the habitual PA patterns observed in children in our cohort, but we might speculate that these occur as a result of socio-cultural influences that surround the working week common to Western culture. Children are introduced to a rigid habitual 7 day weekly cycle composed of 5 days of school followed by two rest/free days as early as the age of 4 years in Australia, and day to day behavioural patterns may exist in line with this culture. Studies examining changes in behaviour according to day of the week are sparse, however there is some support that mood in adults is least positive on Monday ('Blue Monday') and improves over the course of the week with a positive boost on Friday ('Thank God

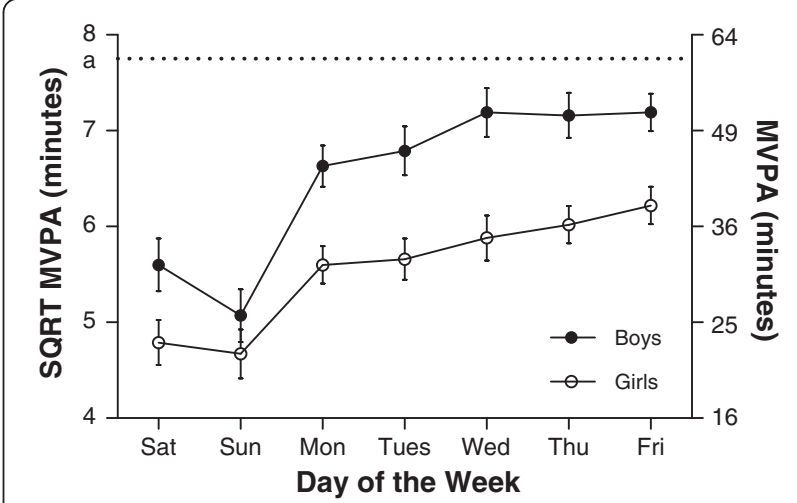

Figure 4 Mean minutes of moderate and vigorous activity (MVPA) (and 95\% confidence intervals) for each day of the week separated by gender. Differences were found for MVPA according to day of the week for both boys and girls (both $p<0.001)$. Overall boys spent more time in MVPA than girls $(p<0.001)$. The horizontal line a represents the published recommended level of 60 mins MVPA per day.

it's Friday') [27]. While the idea that mood changes according to day of the week is far from conclusive, it is possible that children in this study may be adhering to underlying day to day societal trends in terms of habitual physical activity. Intervention efforts aimed at increasing PA may need to overcome daily habits that have been formed early in a child's life and could profit from addressing cultural contingencies surrounding the concept of the working week. There have been various suggestions as to how many days of objectively measured data are enough to adequately reflect PA $[28,29]$. The day to day variation in our data suggests that the full seven days may be needed to provide a realistic measure of habitual activity. Even taking one weekend day would introduce error given the variation seen in PA performed on Saturday and Sunday. Similarly, exclusion of

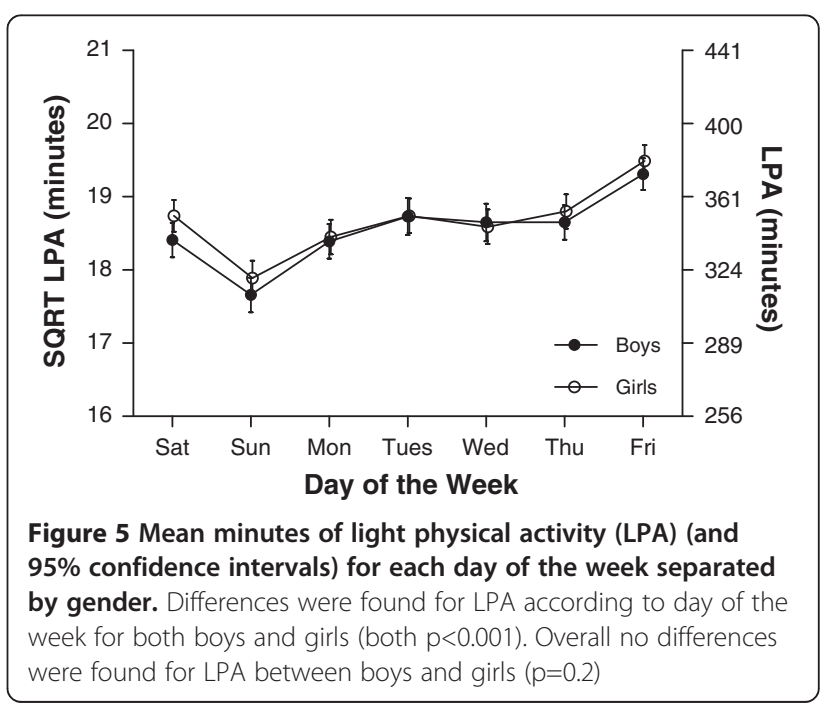




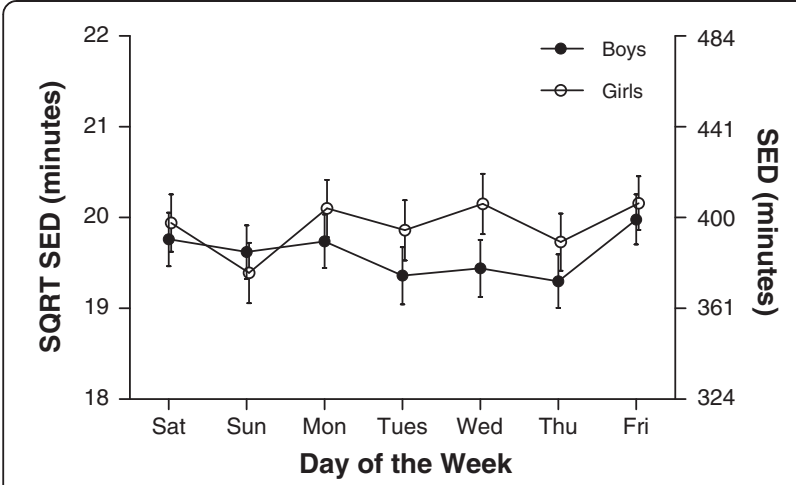

Figure 6 Mean minutes of sedentary physical activity (SED) (and 95\% confidence intervals) for each day of the week separated by gender. Differences were found for SED according to day of the week for both boys and girls (both $p<0.001$ ). Overall girls accumulated more SED per day than boys $(p<0.001)$.

just one day, particularly Monday or Friday may result in different outcomes.

There is also the question of how best to utilize these data in strategies to increase PA in children. One interpretation of our data might be that school based PA interventions should target days early in the week to increase weekly PA, and this may involve targeting the teachers and their influence on their pupils' PA early in the week. On the other hand the large discrepancy between weekday and weekend MVPA might indicate the need to target the parents, together with sports coaches and other adult direct influences on PA of the children in the community and home settings.

\section{Influence of wear time and compliance}

Our primary objective was to investigate total daily PA and how this varied according to day of the week. Consequently, and considering that we discarded potentially invalid data, both on an hourly and daily basis, our interest lay mainly with the summation of accelerometer

Table 4 Unadjusted medians with $5^{\text {th }}$ and $95^{\text {th }}$ percentiles for sedentary, light and moderate and vigorous activity (MVPA) for school time and non-school time, separated by gender

\begin{tabular}{lcc}
\hline & School Time & Non-School Time \\
\hline Sedentary (min) & & \\
\hline Boys & $166(87-238)$ & $209(94-330)$ \\
\hline Girls & $179(89-250)$ & $215(106-323)$ \\
\hline Light (min) & & \\
\hline Boys & $160(84-228)$ & $182(88-277)$ \\
\hline Girls & $154(85-221)$ & $191(94-283)$ \\
\hline MVPA (min) & & \\
\hline Boys & $20(2-58)$ & $19(2-71)$ \\
\hline Girls & $13(2-44)$ & $16(2-58)$ \\
\hline
\end{tabular}

output during the entirety of the day between wake and sleep. However, given that wear time has been shown to influence hourly accelerometer outputs, particularly time spent in sedentary activities in adults [30] it was prudent to introduce wear time into our model to determine whether this variable had any influence on the nature of the physical activity patterns. The absence of any discernible effect after adjusting our model for wear time on the patterns showed, in effect, that if all our participants had equal wear time during the day, the patterns of PA we describe persist.

Corresponding with lower wear time on weekends was the finding of lower accelerometer compliance (fewer children recording a valid day) on these days. While we cannot rule out that compliance influenced daily PA we found no evidence of bias; there was no difference in average daily PA during the week between children who were fully compliant on weekends compared to children who were not (data not shown).

\section{In-school and out of school time}

There are mixed findings in the literature comparing activity levels during school hours and nonschool hours. For example, one study indicated higher levels outside of school [31]. While another showed higher levels during school [32]. In the current study, both boys and girls accumulated more SED and LPA outside of school time than during school time. Our findings are not entirely consistent with findings from a study conducted in 1568 UK 9-10 year old children where it was reported that SED activity was greater outside of school hours for boys but not girls and that both boys and girls performed more vigorous PA outside of school hours than during school [31]. While boys in our cohort accumulated similar amounts of MVPA during and outside of school, girls accumulated more MVPA outside of school hours than in school time. This finding suggests that the girls did not respond to opportunities to be active during school hours as well as boys and supports the premise that different intervention strategies may be required for boys and girls in the school setting $[33,34]$.

\section{Longitudinal trends}

Our data show that the volume of steps taken per day fluctuated from year to year and that there was no evidence of either a systematic increase or decline in volume of PA from age 8 to 12 years. These findings highlight the importance of longitudinal studies carried out over several continuous years in understanding longitudinal trends in PA among children. For example, if we were to only compare data collected in the first and last year of pedometer measures, we may have concluded that PA declined with age. However, if we compared the second and last year we might have concluded 
that there were no changes in PA. The accelerometer variables AC, MVPA and LPA all decreased and SED increased from age 11-12 years. While pedometer steps/ day decreased over the same period, given the fluctuations seen in annual step counts and our lack of accelerometer measures at baseline, it remains unclear whether this provides evidence of a decline in PA as our cohort approached adolescence. While these findings provide support for previous longitudinal studies showing a decline in PA with age in children [15,35], further PA monitoring of our cohort is necessary to answer this question.

Of considerable interest is that the day of the week pattern of PA that existed in our cohort at 8 years was not unique to this age group but persisted in every year of our study through to age 12 years. To our knowledge this is the first study to demonstrate not only a day to day pattern of PA, but also to show that this pattern is consistent in pre-adolescence. Knowledge that persistent patterns exist in elementary school children provides information that can be well utilised in designing interventions to increase PA among youth.

\section{International recommendations}

While comparison to other pedometer studies may be difficult due to cross-population differences in measurements and procedures [36], a recent review concluded that elementary school children should be directed to accumulate 13,000-15,000 steps/day for boys and 11,000-12,000 steps/day for girls to achieve health benefits [25]. Based on these recommendations only 33\% boys and 34\% girls in our study met these suggested step targets. Of particular concern were the low weekend step counts in our cohort, with only $21 \%$ of boys and $18 \%$ of girls meeting step count recommendations on a Sunday. Low weekend activity is consistent with previous literature [4-9] and we add our concerns regarding the PA opportunities available to children on the weekend. Our findings extend this concern to schooldays during the week. During school days, only 36\% of boys and 35\% of girls met stepping recommendations on a Monday compared to $50 \%$ for boys and $45 \%$ of girls on a Friday, and as suggested above, intervention strategies could benefit from targeting days early in the school week.

Similar concerns for the health of our children are raised by the accelerometer data. Our data add a day by day specificity to the incidence of children failing to reach recommended standards. Current guidelines based on previous research and expert opinion suggest that at least 60 minutes of MVPA per day is required in youth for optimal health benefits [26]. In our cohort only $31 \%$ of boys and $16 \%$ of girls met these recommendations. Twenty-nine percent of boys and 15\% of girls met recommendations on a Monday, compared to $39 \%$ of boys and $21 \%$ of girls on a Friday and $16 \%$ of boys and
$10 \%$ of girls on a Sunday. Previous studies have reported a large variation in the percent of children reaching recommended MVPA targets [37]. For example, in a large sample of 12 year old children in the UK, only $4.1 \%$ of boys and $0.9 \%$ of girls were reported as being sufficiently active [6]. Alternatively, in a cohort of 6-11 year-old children in the USA, $48.9 \%$ of boys and $34.7 \%$ of girls surpassed 60 minutes of MVPA/day [38]. In terms of time spent in MVPA our findings of 43 and 32 min per day for boys and girls respectively are slightly higher than a recent pooled analysis of 20,871 children aged 4-18 years [39] where reported values for MVPA were $37 \mathrm{~min}$ per day for boys and $24 \mathrm{~min}$ per day for girls. It should be noted that comparisons of accelerometer results have to be interpreted with some caution, due to variation in methodology adopted by researchers to capture and process accelerometer data such as wear time, valid day and cut-point decisions [21]. It has also been suggested that larger epoch lengths may underreport moderate and vigorous activity and that differing epoch lengths should not be compared [40].

\section{Strengths and weaknesses}

A strong aspect of our study was the substantial size of the cohort and the repeated objective measurements of physical activity over 5 successive years in the same months of the year in a city with consistent weather conditions conducive to outside PA. On the other hand our cohort was limited mainly to children in a medium sized city of relatively homogeneous and mid-range socioeconomic status and may not be generalizable to children of other ethnicities and environments. Furthermore our objective measures of activity do not accurately measure non-ambulatory activities such as swimming and cycling, and our data are dependent on children wearing the pedometers and accelerometers as instructed. Even so, the sensitivity and reliability of our procedures were supported by their detection of daily and yearly patterns in our group. In comparing during and outside of school PA, given the general consistency of bell times of government schools in the region we determined school hours as 9 am $-3 \mathrm{pm}$, however we acknowledge that small variations on bell times may have occurred. Finally it is re-emphasized that our work was confined to the same season of the year. PA has been reported to be season dependent $[6,41]$, and so the pattern which emerged in the spring in our study may not apply to other seasons of the year.

\section{Conclusion}

Our longitudinal data collected for 7 days each year over 5 consecutive years revealed a distinct day to day habitual physical activity pattern. Furthermore this pattern was found to persist from age 8 through to age 12 years. The 
pedometer assessed volume of PA generally increased on school days from Monday through to Friday before declining dramatically over the weekend, and this pattern also applied to the accelerometer assessed volumes and intensity of PA in the last two years. This new knowledge of day of the week patterns may assist public health strategists in designing more specific interventions to increase PA levels in children.

\section{Competing interests}

The authors declare that they have no competing interests.

\section{Authors' contributions}

RMT participated in the design and coordination of the study, collected all data and drafted the manuscript. RC performed the statistical analysis. RDT, $\mathrm{TC}, \mathrm{RD}$ and GW assisted with interpretation and drafting of the manuscript. All authors read and approved the final manuscript.

\section{Author details}

${ }^{1}$ Centre for Research and Action in Public Health, University of Canberra, Bruce ACT 2617, Australia. ${ }^{2}$ Medical School, College of Medicine, Biology and Environment, Australian National University, Canberra ACT 0200, Australia.

${ }^{3}$ Academic Unit of Internal Medicine, Canberra Hospital, Canberra ACT 2606, Australia. ${ }^{4}$ Fenner School of Environment and Society, College of Medicine, Biology and Environment, Australian National University, Canberra ACT 0200, Australia. ${ }^{5}$ Faculty of Health, University of Canberra, Bruce ACT 2617, Australia.

Received: 16 January 2013 Accepted: 12 June 2013 Published: 21 June 2013

\section{References}

1. Dumith SC, Gigante DP, Domingues MR, Kohl HW 3rd: Physical activity change during adolescence: a systematic review and a pooled analysis. Int J Epidemio/ 2011, 40:685-698.

2. Guinhouya BC, Samouda H, Zitouni D, Vilhelm C, Hubert H: Evidence of the influence of physical activity on the metabolic syndrome and/or on insulin resistance in pediatric populations: a systematic review. Int J Pediatr Obes 2011, 6:361-388.

3. Janssen I, Leblanc AG: Systematic review of the health benefits of physical activity and fitness in school-aged children and youth. Int J Behav Nutr Phys Act 2010, 7:40.

4. Duncan JS, Schofield G, Duncan EK: Pedometer-determined physical activity and body composition in New Zealand children. Med Sci Sports Exerc 2006, 38:1402-1409.

5. Duncan MJ, Al-Nakeeb Y, Woodfield L, Lyons M: Pedometer determined physical activity levels in primary school children from central England. Prev Med 2007, 44:416-420.

6. Riddoch CJ, Mattocks C, Deere K, Saunders J, Kirkby J, Tilling K, Leary SD, Blair SN, Ness AR: Objective measurement of levels and patterns of physical activity. Arch Dis Child 2007, 92:963-969.

7. Ziviani J, Macdonald D, Ward H, Jenkins D, Rodger S: Physical activity of young children: a two-year follow-up. Phys Occup Ther Pediatr 2008, 28:25-39.

8. Rowe $\mathrm{D}$, Mahar M, Raedeke T, Lore J: Measuring physical activity in children with pedometers: reliability, reactivity, and replacement of missing data. Pediatr Exerc Sci 2004, 16(4):343-354.

9. Nilsson A, Anderssen SA, Andersen LB, Froberg K, Riddoch C, Sardinha LB, Ekelund U: Between- and within-day variability in physical activity and inactivity in 9- and 15-year-old European children. Scand J Med Sci Sports 2009, 19:10-18.

10. Cox M, Schofield G, Greasley N, Kolt GS: Pedometer steps in primary school-aged children: a comparison of school-based and out-of-school activity. J Sci Med Sport 2006, 9:91-97.

11. Tudor-Locke C, Lee SM, Morgan CF, Beighle A, Pangrazi RP: Children's pedometer-determined physical activity during the segmented school day. Med Sci Sports Exerc 2006, 38:1732-1738.
12. Dencker M, Bugge A, Hermansen B, Andersen LB: Objectively measured daily physical activity related to aerobic fitness in young children. J Sports Sci 2010, 28:139-145.

13. Riddoch CJ, Bo Andersen L, Wedderkopp N, Harro M, Klasson-Heggebo L, Sardinha LB, Cooper AR, Ekelund U: Physical activity levels and patterns of 9- and 15-yr-old European children. Med Sci Sports Exerc 2004, 36:86-92.

14. Francis SL, Morrissey JL, Letuchy EM, Levy SM, Janz KF: Ten-year objective physical activity tracking: lowa bone development study. Med Sci Sports Exerc 2013: . Published online ahead of print March 6.

15. Ridgers ND, Timperio A, Crawford D, Salmon J: Five-year changes in school recess and lunchtime and the contribution to children's daily physical activity. Br J Sports Med 2012, 46:741-746.

16. Telford RD, Cunningham RB, Telford RM: Day-dependent step-count patterns and their persistence over 3 years in 8-10-year-old children: the LOOK project. Ann Hum Biol 2009, 36:669-679.

17. Telford RD, Bass SL, Budge MM, Byrne DG, Carlson JS, Coles D, Cunningham RB, Daly RM, Dunstan DW, English R, et al: The lifestyle of our kids (LOOK) project: outline of methods. J Sci Med Sport 2009, 12:156-163.

18. Beets MW, Patton MM, Edwards S: The accuracy of pedometer steps and time during walking in children. Med Sci Sports Exerc 2005, 37:513-520.

19. Trost SG, Loprinzi PD, Moore R, Pfeiffer KA: Comparison of accelerometer cut points for predicting activity intensity in youth. Med Sci Sports Exerc 2011, 43:1360-1368.

20. Evenson KR, Catellier DJ, Gill K, Ondrak KS, McMurray RG: Calibration of two objective measures of physical activity for children. J Sports Sci 2008, 26:1557-1565

21. Cain KL, Sallis JF, Conway TL, Van Dyck D, Calhoon L: Using accelerometers in youth physical activity studies: a review of methods. J Phys Act Health: . Published online ahead of print July 9, 2012.

22. Mattocks C, Leary S, Ness A, Deere K, Saunders J, Tilling K, Kirkby J, Blair SN, Riddoch C: Calibration of an accelerometer during free-living activities in children. Int J Pediatr Obes 2007, 2:218-226.

23. Galway NW: Introduction to Mixed Modelling: Beyond Regression and Analysis of Variance. ; 2006. ISBN 978-0-470-01496-7.

24. Kenward $M G$, Roger $\mathrm{JH}$ : Small sample inference for fixed effects from restricted maximum likelihood. Biometrics 1997, 53:983-997.

25. Tudor-Locke C, Craig CL, Beets MW, Belton S, Cardon GM, Duncan S, Hatano Y, Lubans DR, Olds TS, Raustorp A, et al: How many steps/day are enough? For children and adolescents. Int J Behav Nutr Phys Act 2011 8:78.

26. U.S. Department of Health and Human Services: Office of Disease Prevention and Health Promotion--Healthy People 2010. Nasnewsletter 2000, 15:3.

27. Stone AA, Schneider S, Harter JK: Day-of-week mood patterns in the United States: on the existence of 'Blue Monday', 'Thank God it's Friday' and weekend effects. Journal of Positive Psychology 2012, 7:306-314

28. Trost SG, Pate RR, Freedson PS, Sallis JF, Taylor WC: Using objective physical activity measures with youth: how many days of monitoring are needed? Med Sci Sports Exerc 2000, 32:426-431.

29. Baranowski T, Masse LC, Ragan B, Welk G: How many days was that? We're still not sure, but we're asking the question better! Med Sci Sports Exerc 2008, 40:S544-S549.

30. Tudor-Locke C, Johnson WD, Katzmarzyk PT: U.S. population profile of time-stamped accelerometer outputs: impact of wear time. J Phys Act Health 2011, 8:693-698.

31. Steele RM, van Sluijs EM, Sharp SJ, Landsbaugh JR, Ekelund U, Griffin SJ: An investigation of patterns of children's sedentary and vigorous physical activity throughout the week. Int J Behav Nutr Phys Act 2010, 7:88.

32. Nyberg GA, Nordenfelt AM, Ekelund U, Marcus C: Physical activity patterns measured by accelerometry in 6- to 10-yr-old children. Med Sci Sports Exerc 2009, 41:1842-1848.

33. Verloigne M, Van Lippevelde W, Maes L, Yildirim M, Chinapaw M, Manios Y Androutsos O, Kovacs E, Bringolf-Isler B, Brug J, De Bourdeaudhuij I: Levels of physical activity and sedentary time among 10- to 12-year-old boys and girls across 5 European countries using accelerometers: an observational study within the ENERGY-project. Int J Behav Nutr Phys Act 2012, 9:34

34. Bailey DP, Fairclough SJ, Savory LA, Denton SJ, Pang D, Deane CS, Kerr CJ: Accelerometry-assessed sedentary behaviour and physical activity levels during the segmented school day in 10-14-year-old children: the HAPPY study. Eur J Pediatr 2012, 171:1805-1813. 
35. Basterfield L, Adamson AJ, Frary JK, Parkinson KN, Pearce MS, Reilly JJ: Longitudinal study of physical activity and sedentary behavior in children. Pediatrics 2011, 127:e24-e30

36. Beets MW, Bornstein D, Beighle A, Cardinal BJ, Morgan CF: Pedometermeasured physical activity patterns of youth: a 13-country review. Am J Prev Med 2010, 38:208-216.

37. Ekelund U, Tomkinson G, Armstrong N: What proportion of youth are physically active? Measurement issues, levels and recent time trends. $\mathrm{Br}$ J Sports Med 2011, 45:859-865.

38. Troiano RP, Berrigan D, Dodd KW, Masse LC, Tilert T, McDowell M: Physical activity in the United States measured by accelerometer. Med Sci Sports Exerc 2008, 40:181-188.

39. Ekelund U, Luan J, Sherar LB, Esliger DW, Griew P, Cooper A: Moderate to vigorous physical activity and sedentary time and cardiometabolic risk factors in children and adolescents. JAMA: J Am Med Assoc 2012, 307:704-712.

40. Edwardson $\mathrm{CL}$, Gorely $\mathrm{T}$ : Epoch length and its effect on physical activity intensity. Med Sci Sports Exerc 2010, 42:928-934.

41. Rich C, Griffiths $\sqcup$, Dezateux C: Seasonal variation in accelerometerdetermined sedentary behaviour and physical activity in children: a review. Int J Behav Nutr Phys Act 2012, 9:49.

doi:10.1186/1479-5868-10-81

Cite this article as: Telford et al.: Longitudinal patterns of physical activity in children aged 8 to 12 years: the LOOK study. International Journal of Behavioral Nutrition and Physical Activity 2013 10:81.

\section{Submit your next manuscript to BioMed Central and take full advantage of:}

- Convenient online submission

- Thorough peer review

- No space constraints or color figure charges

- Immediate publication on acceptance

- Inclusion in PubMed, CAS, Scopus and Google Scholar

- Research which is freely available for redistribution 